\title{
IDEOLOGIA E CONSTRUÇÃO \\ DE IDENTIDADES EM UMA AUDIÊNCIA DE CONCILIAÇÃO NO PROCON ${ }^{1}$
}

\section{IDEOLOGÍA Y CONSTRUCCIÓN DE IDENTIDADES EN UNA AUDIENCIA DE CONCILIACIÓN EN EL PROCON}

\author{
IDEOLOGY AND CONSTRUCTION OF IDENTITIES IN A CONCILIATION HEARING AT \\ PROCON
}

\author{
Maurício Carlos da Silva* \\ Amitza Torres Vieira** \\ Universidade Federal de Juiz de Fora
}

RESUMO: O artigo propõe identificar o papel da ideologia na construção de identidades em uma audiência de conciliação no PROCON, a partir de um estudo qualitativo com dados reais de fala. Nesse contexto institucional, a negociação entre as partes, reclamante e reclamado, depende de uma intensa construção discursiva de versões sobre o fato. Considera-se a concepção de ideologia enquanto sentido negociado (BILLIG, 1991; SHI-XU, 2000; THOMPSON, 2011) e a noção de identidade como um construto interacional (BUCHOLTZ; HALL, 2004; OCHS, 1993; MOITA LOPES, 2001). Os resultados do estudo mostram que a dimensão ideológica serviu para fornecer status de factualidade a opiniões subjetivas (SHI-XU, 2000), atuando no sentido de orientar a significação do processo de construção e sustentação de identidades dos reclamados como maus profissionais x bons profissionais.

PALAVRAS-CHAVE: Ideologia. Identidade. Audiência de conciliação no PROCON.

\footnotetext{
${ }^{1}$ O presente trabalho foi realizado com apoio da Coordenação de Aperfeiçoamento de Pessoal de Nível Superior - Brasil ( C A P ES)

* Doutorando em Linguística pela Universidade Federal de Juiz de Fora. Professor do Instituto Federal do Sudeste de Minas Gerais - Campus SãoJoãoDel-Rei. E-mail: maucasil@yahoo.com.br.

** Doutora em Estudos da Linguagem pela Pontifícia Universidade Católica do Rio de Janeiro e Pós-Doutora em Estudos da Linguagem pela Universidade Federal Fluminense. Professora do Programa de Pós-Graduaça em Linguística da Universidade Federal de Juiz de Fora. E-mail: amitzatv@yahoo.com.br.
} 
RESUMEN: El artículo propone identificar el papel de la ideología en la construcción de identidades en una audiencia de conciliación en el PROCON, a partir de un estudio cualitativo con datos reales de habla. En ese contexto institucional, la negociación entre las partes, reclamante y reclamado, depende de una intensa construcción discursiva de versiones sobre el hecho. Se considera la concepción de ideología como sentido negociado (BILLIG, 1991; SHI-XU, 2000, THOMPSON, 2011) y la noción de identidad se toma, también, como un constructo interactivo (BUCHOLTZ; HALL, 2004; OCHS, 1993; MOITA LOPES, 2001). Los resultados del estudio demuestran que la dimensión ideológica sirvió para proporcionar status de algo fáctico a opiniones subjetivas (SHI-XU, 2000) y tuvo la función de orientar la significación en el proceso de construcción y sustentación de identidades de los reclamados como malos

PALABRAS CLAVE: Ideología. Identidad. Audiencia de conciliación en PROCON.

ABSTRACT: The paper proposes to identify the role of ideology in the construction of identities in a conciliation hearing at PROCON by carrying out a qualitative case study with actual data of talk. In this institutional context, negotiation between the parties, claimant and claimed, depends on an intense discursive construction of versions of a fact. In the paper, ideology is conceived as a negotiated sense in the interactional situation (BILLIG, 1991; SHI-XU, 2000; THOMPSON, 2011). Similarly, the notion of identity is taken as an interactional construct. These concepts are fluid and fragmented, negotiated and maintained or refuted by the participants in the social encounter (BUCHOLTZ; HALL, 2004; OCHS, 1993; MOITA LOPES, 2001). The results of the study show that the ideological dimension served, as postulated by Shi-xu (2000), to provide the status of factuality to subjective opinions and had the function of guiding the meaning in the process of building and sustaining identities of those claimed as bad professionals vs. good professionals.

KEYWORDS: Ideology. Identity. Conciliation hearing at PROCON.

\section{INTRODUÇÃO}

As audiências de conciliação no PROCON, órgão de defesa do consumidor, acontecem após reclamações apresentadas por consumidores, denominados reclamantes, que manifestam insatisfação pelo serviço prestado ou pelo produto adquirido. $\mathrm{O}$ reclamado, que pode ser representado pelo gerente ou por um advogado da empresa, é chamado a participar de um encontro com o reclamante. O evento é intermediado por um conciliador da instituição, para que o problema seja resolvido sem se recorrer a instâncias do judiciário. Nesse contexto institucional, a negociação entre as partes depende de uma intensa construção discursiva de versões sobre o ocorrido.

Como as versões de reclamante e reclamado geralmente divergem, algumas dessas negociações constituem exemplos do que se denomina fala de conflito (GRIMSHAW, 1990), uma área distinta de pesquisa que lida centralmente com o estudo do conflito nas suas mais variadas formas (BRENNEIS, 1988). Segundo essa perspectiva, um conflito é identificado "[...] quando os participantes opõem seus enunciados, ações ou selfs uns dos outros, ao longo de sucessivos turnos de fala [...]” (VUCHINICH, 1990, p. 118). Nesse caso, recursos linguísticos, paralinguísticos ou sinestésicos podem ser usados para expressar oposição, direta ou indiretamente.

Em uma análise preliminar dos corpora com dados de audiências no PROCON, foram identificadas sequências de conflito nas quais elementos linguístico-discursivos com dimensões ideológicas reconhecidas e partilhadas eram trazidos à interação pelas partes. Esse primeiro olhar sobre os dados mostrou também que, nessas sequências conversacionais, a ideologia estava ligada à co-construção de identidades dos participantes. A partir dessa observação, surgiu o questionamento que motivou este estudo: como atua a ideologia na construção de identidades em audiências de conciliação no PROCON? Mais especificamente, questiona-se como essas ideologias são linguística e discursivamente coconstruídas nessa situação de fala de conflito.

No intuito de responder a essas questões, foi selecionada, como objeto de estudo, uma audiência de conciliação no PROCON que trata da insatisfação de um casal sobre serviços prestados em sua residência por dois pedreiros. O trabalho, de cunho qualitativo e interpretativo, se propõe a investigar o papel da ideologia na construção de identidades nessa situação de fala institucional. De modo particular, pretende-se identificar os recursos linguístico-discursivos utilizados pelas partes em conflito para construir e desconstruir suas identidades sob bases ideológicas. 
O conceito de ideologia assumido neste trabalho considera que ideologias são instáveis, situadas e influenciadas por contextos relevantes, abrangendo não só o contexto político, mas toda a ordem social. Nessa abordagem, a ideologia pode ser evidenciada pelas práticas interacionais e o próprio senso comum é considerado uma manifestação ideológica (BILLIG, 1991). Essa visão rompe com a ideia reducionista de ideologia apenas como ferramenta a serviço das classes dominantes, pois a própria opinião de indivíduos particulares, grupos ou instituições tem importância social e serve a propósitos ideológicos (SHI-XU, 2000). Enfim, é interesse desta investigação a concepção de ideologia enquanto sentido negociado/construído na situação interacional, por meio das formas simbólicas $^{2}$ (THOMPSON, 2011) que estão inseridas nos contextos sociais e que circulam no mundo social.

No que tange à identidade, parte-se do princípio de que ela emerge durante a interação, é construída e circula no contexto discursivo local (BUCHOLTZ; HALL, 2004), e está orientada para metas específicas (HALL, 2000). Compreende-se também que as identidades podem ser reconfiguradas e modificadas a partir das reações dos interagentes (OCHS, 1993), que podem assumir não apenas uma, mas diversas identidades no decorrer de uma mesma interação (MOITA LOPES, 2001).

Compreender como as construções identitárias são orientadas por dimensões ideológicas pode colaborar para a prática profissional de mediadores, cuja meta institucional é produzir o acordo entre as partes.

\section{A PERSPECTIVA SOCIOINTERACIONAL}

Como filiação teórica, este trabalho se insere na Sociolinguística Interacional (SI), que leva em consideração a análise da linguagem em contextos reais de uso. Essa perspectiva proposta por Gumperz (2002) alia-se à análise sociológica de Goffman (2002) para focalizar a prática comunicativa no mundo real em que as forças interativas e sociais emergem. Nesse entendimento, a linguagem é vista como um sistema simbólico construído social e culturalmente, e seu uso reflete os significados de macro nível social - por exemplo, identidade do grupo, diferenças de status - e cria significados de micro nível social - o que alguém está dizendo em um dado momento - (SCHIFFRIN, 1994).

De acordo com Gumperz (2002), os processos interpretativos ocorrem por meio das pistas de contextualização, isto é, quaisquer traços linguísticos, paralinguísticos e não-linguísticos (gestos, postura etc.) que contribuem para assinalar as pressuposições contextuais. Essas marcas possibilitam aos participantes inferir intenções comunicativas e interpretar em que atividade estão operando. As pistas de contextualização atuam, assim, no estabelecimento de enquadres ${ }^{3}$ (GOFFMAN, 2002) no curso da interação. O locutor sinaliza e o interlocutor interpreta qual atividade está sendo encenada.

Junto à noção de enquadre, Goffman (2002) desenvolve o conceito de footing, que está relacionado ao aspecto dinâmico da interação, às diferentes projeções dos interlocutores no discurso. A partir dessa constatação, o autor caracteriza o alinhamento ${ }^{4}$, a postura dos participantes em uma dada situação social. As mudanças de footing são constituídas e evidenciadas em grande parte pelas mudanças na "estrutura de participação" da fala, conceito desenvolvido por Goffman (2002). O autor mostra as complexas relações discursivas presentes nos formatos de produção (relativo ao falante) e de participação (relativo ao ouvinte). As noções de falante e ouvinte são decompostas, tratando do falante como: animador, indivíduo que produz as elocuções; autor, aquele que seleciona os sentimentos que estão sendo expressos e as palavras nas quais eles são codificados; responsável, alguém cuja posição social é estabelecida, alguém comprometido com o que as palavras expressam.

\footnotetext{
${ }^{2}$ Formas simbólicas são entendidas como “[...] um amplo espectro de ações e falas, imagens e textos, que são produzidos por sujeitos e reconhecidos por eles e outros como construtos significativos (THOMPSON, 2011, p. 79).

${ }^{3} \mathrm{O}$ conceito de enquadre refere-se à definição do que está acontecendo em uma interação, em qual atividade os participantes estão engajados e qual sentido eles dão ao que dizem.

${ }^{4} \mathrm{O}$ alinhamento representa a projeção do eu assumida pelo interlocutor em sua relação com os outros, consigo próprio e com o discurso em construção.
} 
Em relação à estrutura de participação do ouvinte, Goffman (2002) distingue entre ouvinte ratificado, aquele que possui um espaço reconhecido no momento de fala; ouvinte intrometido, aquele que escuta às escondidas de forma proposital, que não é percebido pelos outros participantes de forma oficial no evento comunicativo; e ouvinte por acaso, aquele que ouve de forma acidental, sem pretensões de fazê-lo. Entre os ouvintes ratificados, Goffman (2002) diferencia o interlocutor endereçado - a quem o falante dispensa sua atenção e de quem se espera que se torne o próximo falante - do interlocutor não-endereçado, aquele que, apesar de participar do momento de fala, não é o foco direto do falante atual, o que não o impede de tomar o turno se lhe aprouver.

Na sequência, são estabelecidos os conceitos de ideologia e identidade assumidos neste estudo, a partir de uma perspectiva interacional.

\subsection{IDEOLOGIA COMO PARTE CONSTITUTIVA DA VIDA EM SOCIEDADE}

Historicamente, o conceito mais duradouro de ideologia pode ser creditado a Marx e Engels (2009), que a consideravam como um sistema de ideias materializado na religião, na metafísica, na moral etc. Esse sistema era usado como ferramenta pela classe dominante para distorcer a realidade e criar uma falsa consciência das coisas, apresentando de forma ilusória as ideias de seus interesses como sendo a realidade verdadeira. Defendiam que as ideias são produtos dos homens, mas esse homem não é pessoa livre, pois é limitado por sua condição produtiva e pelas relações no espaço social.

Esse conceito unitário e monolítico não é aqui tratado; ao contrário, considera-se a ideologia como um sistema de ideias instável, situado e influenciado por contextos relevantes, abrangendo toda a ordem social. Esse sentido é encontrado em Billig (1991) que considera ideologia um conceito multifacetado e complexo, caracterizado por contradições e ambiguidades, sofrendo influências culturais e variações no curso da história. Essa posição se distancia também da noção marxista ao afirmar que "A pessoa comum o sujeito da ideologia - não é um joguete cego, cuja mente tem sido preenchida por forças externas e reage sem pensar. O sujeito da ideologia é um ser retórico que pensa e argumenta com ideologia"5 (BILLIG, 1991, p. 2). Essa noção, portanto, ultrapassa a formação e a divisão de classes embasada por questões materialistas; ela abrange toda a ordem social e pode ser evidenciada nas práticas interacionais. A ideologia, portanto, é parte constitutiva da existência em sociedade, visto que, para o autor, valores e opiniões comumente sustentados são eles próprios produtos culturais, e o próprio senso comum é uma forma de ideologia.

Nessa mesma linha, Shi-Xu (1992) defende que opiniões transmitem uma crença ideológica, por expressarem uma moral partilhada ou aceita. Para o autor, as opiniões são amparadas na coletividade cultural e podem ser inferidas a partir de fatos culturais objetivos trazidos ao discurso. As opiniões revelam normas sociais ou institucionais que projetam avaliação sobre o outro, refletindo o julgamento moral de alguém (SHI-XU, 2000). O autor destaca, ainda, que as opiniões não são apenas argumentativamente orientadas, mas também estão conectadas a ideologias, que funcionam como base de realidade para opiniões subjetivas, conferindo a estas uma aparência de factualidade. Nos dados analisados pelo autor, sustentações objetivas ideologicamente orientadas atuam na argumentação como um frame interpretativo para a opinião expressa.

Mais recentemente, Thompson (2011) construiu uma definição relativamente ampla de ideologia, sendo compreendida por ele como o sentido a serviço da dominação. O autor esclarece, ainda, que o sentido pelo qual está interessado é aquele mobilizado pelas formas simbólicas, que estão inseridas nos contextos sociais e que circulam no mundo social. Em sua proposta, nenhuma forma simbólica é ideológica por si mesma, isso será determinado na interação social, depende da maneira como é usada e entendida em contextos sociais específicos. Por essa razão, pode-se interpretar uma forma simbólica como sendo ideológica em um determinado contexto e como não sendo em outro.

A partir desta breve retomada da noção de ideologia, ela passou a ser considerada, neste trabalho, não como ferramenta de manipulação da realidade a serviço de ideais políticos, mas como parte constitutiva da sociedade. Nesse sentido, a ideologia é

${ }^{5}$ The ordinary person - the 'subject' of ideology - is not a blind dupe, whose mind has been filled by outside forces and who reacts unthinkingly. The subject of ideology is a rhetorical being who thinks and argues with ideology. (Tradução nossa). 
influenciada por seu contexto situacional, o que a torna um fenômeno dinâmico e mutável. Ela está materializada em ações humanas, em crenças e valores morais, devendo, portanto, ser acessada por meio da observância da interação social. Por sua vez, $o$ sujeito social é considerado não como ser ingênuo e insensível, mas como alguém capaz de reagir a uma ideologia valendo-se dela mesma.

\subsection{IDENTIDADE COMO CONSTRUÇÃO SOCIOINTERACIONAL}

O conceito de identidade é objeto de estudo de muitos pesquisadores sob diferentes aspectos. Nesta pesquisa, a noção não é considerada a priori, como categoria social fixa e estável. As identidades são entendidas aqui como um construto interacional, por isso são fluidas e fragmentárias, negociadas e mantidas ou refutadas pelos participantes no momento da interação social.

Para Hall (2000), por exemplo, as identidades são construídas dentro e não fora do discurso, produzidas em locais históricos e institucionalmente específicos, no interior de formações e práticas discursivas específicas, por estratégias e iniciativas particulares. O que nos permite dizer que, ao se estudar as identidades construídas em uma dada interação, deve-se considerar as informações relacionadas ao contexto histórico, social e cultural nos quais se situam as construções identitárias.

Bucholtz e Hall (2004, p.585-586) estudam a identidade a partir de uma relação de intersubjetividade. Para as autoras, trata-se de "[...] um fenômeno relacional e sociocultural que emerge e circula no contexto discursivo local de interação e não como uma estrutura estável localizada principalmente na mente individual ou em categorias sociais fixas".

De acordo com Ochs (1993), a identidade projetada por um indivíduo deve ser confirmada ou rejeitada pelos outros membros da interação, uma vez que as projeções de identidade estão sempre sujeitas ao reconhecimento e à avaliação social. Para a autora, os falantes podem construir não apenas suas próprias identidades, mas também as identidades sociais dos outros interlocutores.

Moita Lopes (2001) também considera a identidade em termos de pluralidade. Para o autor, não apenas uma, mas diversas podem ser as identidades assumidas por um mesmo indivíduo no decorrer de uma interação. Dessa forma, "[...] entender as identidades sociais, metaforicamente, como um mosaico parece ser mais revelador de como as pessoas vivem a vida social, se modificando na dependência das práticas discursivas em que atuam" (MOITA LOPES, 2001, p.62).

Essa visão de identidade, enquanto mosaico, permite pensar que uma ou outra identidade poderá ganhar destaque conforme interesses e conveniências interacionais. Isso exigirá, no processo de análise, observar não que identidade as pessoas têm, mas quais identidades estão sendo construídas e ganhando relevância por intermédio do discurso.

\section{METODOLOGIA}

Para alcançar os objetivos propostos neste trabalho, desenvolve-se uma pesquisa de base qualitativa, tomando-a como uma prática interpretativa. Assim, pretende-se entender e explicar os fenômenos sociais a partir dos contextos naturais onde eles acontecem (DENZIN; LINCOLN, 2006).

Os dados em análise foram gravados em áudio e, posteriormente, transcritos com o intuito de registrar materialmente a forma como os participantes utilizam a linguagem para produzir entendimentos. Para representar a conversa com o máximo de detalhes possível, optou-se por utilizar como modelo de transcrição um sistema gráfico que possibilitasse marcar pausas, hesitações, interrupções, ênfases, etc., adaptado de Sacks, Schegloff e Jefferson (1974) ${ }^{6}$.

\footnotetext{
${ }^{6}$ As convenções usadas na transcrição dos dados encontram-se no ANEXO A.
} 
Realizou-se um estudo de caso, em uma audiência de conciliação no PROCON . Para Yin (2001), esse tipo de investigação científica é adequado para responder questões do tipo "como e por quê". Em um estudo de caso, um fenômeno contemporâneo é estudado em seu contexto real, especialmente quando os limites entre o fenômeno e o contexto não estão claramente definidos.

As audiências de conciliação no PROCON compreendem três fases, identificadas por Oliveira (2010) da seguinte forma: (i) enquadre legal da reclamação, fase na qual são apresentadas as versões de reclamante e reclamado sobre o ocorrido; (ii) atribuição de responsabilidades, fase na qual os participantes atribuem responsabilidades pelo problema que originou a reclamação; e (iii) produção de acordo, fase em que os participantes, auxiliados pelo mediador, oferecem propostas a fim de solucionar o problema. Essa estrutura não é fixa, podendo os momentos se sobrepor uns aos outros.

As interações institucionais, tal como a analisada aqui, envolvem geralmente uma redução na variedade de práticas interacionais disponíveis aos participantes. Como sugerem Drew e Heritage (1992), o ambiente e a identidade profissional determinam e restringem o tipo de interação aceitável para um dado momento específico. Para Maynard (1984), as interações institucionais são pautadas pela necessidade de realização de uma meta, por isso tendem a desenvolver formatos organizacionais para o cumprimento dessa meta, que no caso em questão é chegar a um acordo.

A audiência de conciliação que compõe o corpus deste estudo recebe o nome de Super Gesso e os participantes são: a reclamante, Sandra; os reclamados, Pedro e Carlos ${ }^{8}$; e a mediadora, Flávia ${ }^{9}$. O conflito tem como ponto motivador a insatisfação da consumidora em relação aos serviços de instalação de gesso em sua residência. Nessa audiência, o acordo não foi celebrado e a mediadora sugeriu que o caso fosse encaminhado para a justiça.

\section{IDEOLOGIA E COCONSTRUÇÃO DE IDENTIDADES}

Começamos a análise considerando o início da interação, quando a mediadora reconhece o reclamado Pedro como ouvinte ratificado, ou seja, espera-se que ele seja o próximo falante para poder fazer seu relato dos fatos, o que ocorre a partir da linha 03.

\section{Excerto 1: Nós fomos indicados}

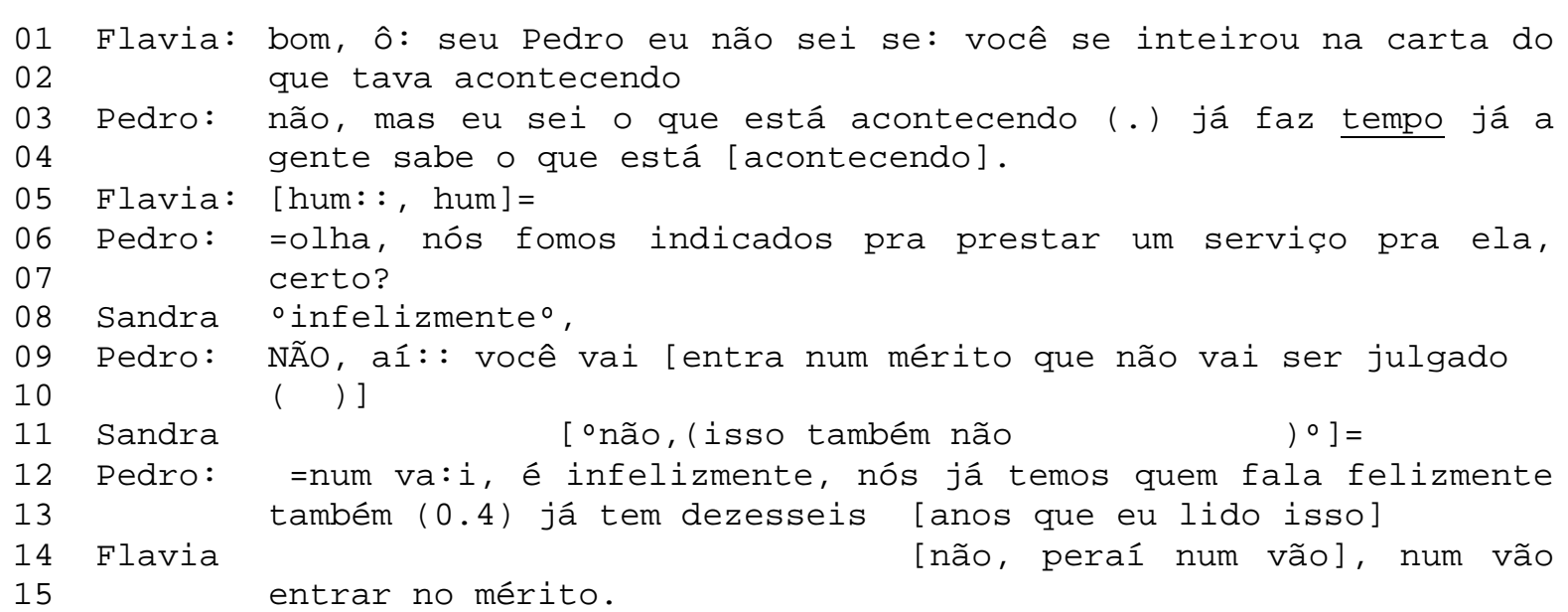

\footnotetext{
${ }^{7}$ A pesquisa foi aprovada pelo Comitê de Ética da Universidade Federal de Juiz de Fora por meio do parecer no CAAE: 00620912.0.0000.5147.

${ }^{8} \mathrm{Na}$ audiência, Carlos não se manifesta verbalmente, cabendo a Pedro defender a posição da empresa.

${ }^{9}$ Em respeito à ética, todos os nomes citados são fictícios.
} 
Pedro começa seu relato (linha 06) se direcionando à mediadora. Para amparar sua fala, busca um dado da coletividade cultural (SHI-XU, 2000), a questão de terem sido indicados, que possui um valor ideológico positivo, uma vez que caracteriza o reconhecimento profissional por serviços prestados a outros. Essa estratégia funciona como recurso para conferir status factual a uma opinião subjetiva (SHI-XU, 2000). Assim, a afirmação de terem sido recomendados é uma tentativa do reclamado de atribuir a si a identidade de bom profissional, o que coloca em dúvida estarem ali na condição de reclamados.

No entanto, Sandra, a reclamante, que não era a interlocutora endereçada para aquele momento, rompe a fase de enquadre legal da reclamação sobrepondo sua fala ao fazer uma avaliação negativa (infelizmente) da indicação recebida. A reclamante demostra não estar alinhada ao enquadre institucional de audiência e instaura com o reclamado um novo enquadre - bate boca (linhas 08 a 13). Pedro, nesse novo enquadramento (linhas 12 e 13), segue com seu objetivo de construir uma identidade de bom profissional e para isso recorre ao elemento do senso comum - tempo de serviço -, que ideologicamente também possui um valor positivo, pois denota experiência e qualificação para o serviço.

Nas linhas 14 e 15, a mediadora se sobrepõe à fala do reclamado na tentativa de reenquadramento da institucionalidade da atividade. Flávia consegue seu intento e a fase inicial da audiência, na qual cada uma das partes narra sua versão do evento, é retomada, como pode ser observado no excerto seguinte, em que o reclamado relata sua versão sobre o ocorrido.

Excerto 2: O projeto não fomos nós

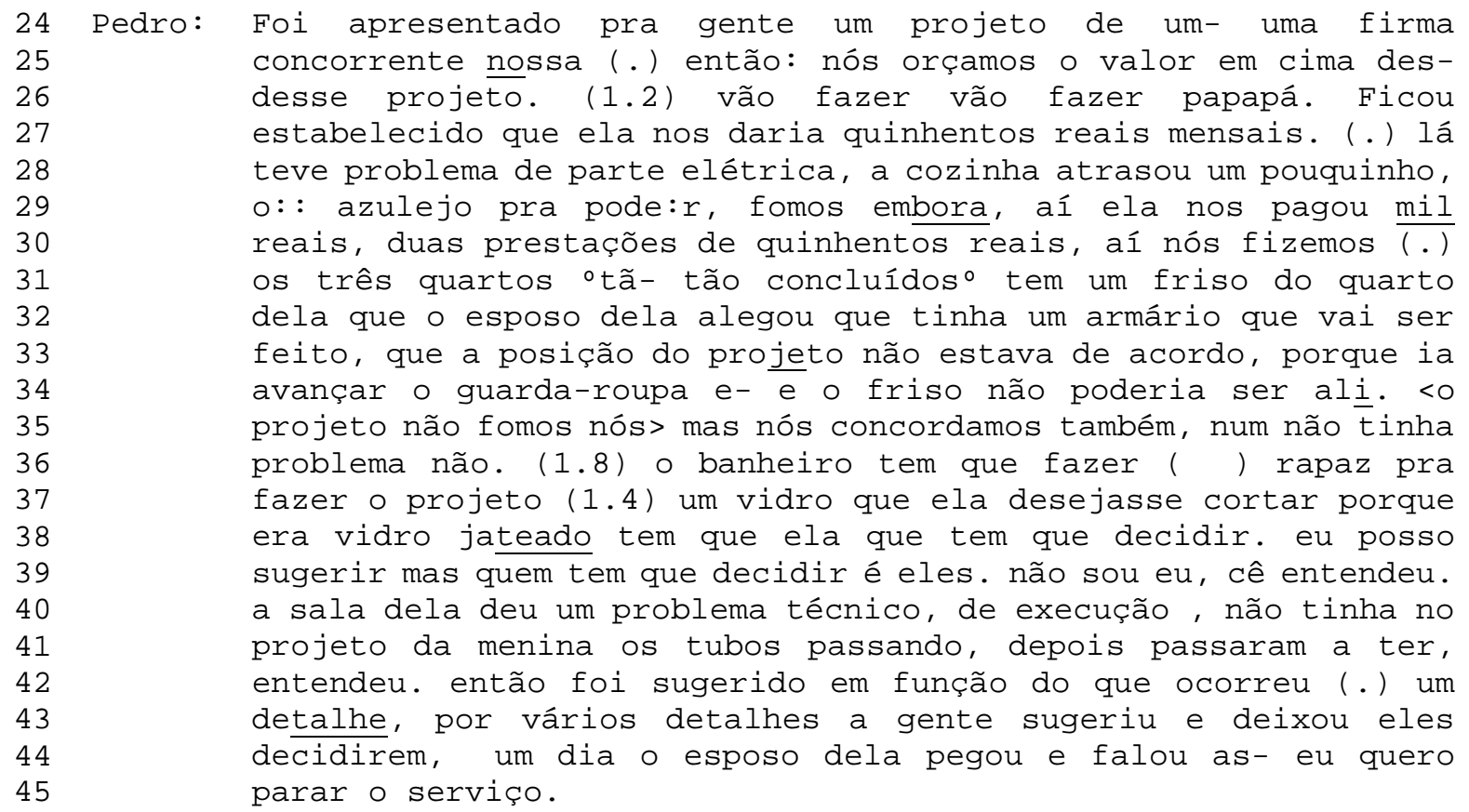

Esse excerto é parte do relato de Pedro sobre o que ocorrera. Nele, o reclamado deixa claro que o projeto da obra já veio pronto, portanto se exime da responsabilidade em relação a ele (linhas 24 a 26). Na sequência, expõe problemas de atraso na construção da casa e no projeto (linhas 28 a 39) que impediram a continuação dos seus serviços. Para tanto, recorre a um discurso reportado, dando voz ao marido da reclamante, que se torna responsável pela afirmação (o esposo dela alegou que tinha um armário que vai ser feito, que a posição do projeto não estava de acordo). Shi-xu (2000) aponta que opiniões podem ser também mediadas por outras vozes, seja de indivíduos, grupos ou instituições, de forma que produzam efeitos desejáveis. No caso desse excerto, Pedro anima a voz do marido da reclamante como estratégia argumentativa para sustentar sua opinião.

Usando da elevação do tom de voz, o reclamado chama a atenção para o projeto e reforça que este não era de sua autoria (o projeto não fomos nós), argumento reiterado na linha 41, quando deixa marcado que a autoria é de outra pessoa (projeto da menina). A 
escolha do termo "menina" para caracterizar a autora do projeto é mais um intento de desqualificá-lo, pois ideologicamente, em nossa cultura, esse termo refere-se a uma pessoa frágil, de pouca idade, portanto, inexperiente e imatura. $\mathrm{Na}$ linha 45 , usando novamente o discurso reportado, Pedro anima a voz do esposo de Sandra, que se torna autor e responsável pelo dito que levou à paralização da obra (o esposo dela pegou e falou as-eu quero parar o serviço).

Sandra, no entanto, se opõe às contribuições verbais de Pedro e acrescenta outras informações relevantes para a constituição da realidade dos fatos que geraram o conflito, como se pode observar no excerto a seguir.

\section{Excerto 3: Só iam pra receber o dinheiro}

$\begin{array}{lll}61 & \text { Flavia } & \text { sandra, a senhora tem alguma coisa a [fala:] } \\ 62 & \text { Sandra: } & \text { [flávia] <o negócio é o } \\ 63 & \text { seguinte>, desde o início começou-se o serviço eles trabalhavam } \\ 64 & \text { TRÊS DIAS e só iam pra receber dinheiro no meu serviço. isso } \\ 65 & \text { aconteceu duas vezes. eu já até coloquei pra você. sendo que } \\ 66 & \text { esses detalhes se vai por vidro ou não, depois: : o- o carlos } \\ 67 & \text { conversou com o lucas e falou, <conversou com o cara do vidro> } \\ 68 & \text { e falou, a gente não tem condição de pôr vidro agora, aí o cara } \\ 69 & \text { do vidro falou olha, vocês mandam fazer o acabame: nto que tem } \\ 70 & \text { que ser feito depois a gen- quando você puder vocês encaixam o } \\ 71 & \text { vidro. }\end{array}$

Nesse excerto, Flávia endereça a interlocução a Sandra, abrindo espaço para que ela possa exercer seu direito de fala (linha 61). A mediadora obedece, dessa forma, à organização da interação institucional do PROCON, na qual as partes têm assegurada a oportunidade de expressar suas visões sobre o evento.

A reclamante inicia sua narrativa fazendo referência a uma situação concreta para avaliar negativamente a conduta dos reclamados, atribuindo a eles a identidade de maus profissionais (linhas 63 e 65) (desde o início começou-se o serviço eles trabalhavam TRÊS DIAS e só iam pra receber dinheiro). A ênfase dada à quantidade de dias trabalhados e algumas outras pistas contextuais presentes na fala de Sandra, como a marcação temporal (desde o início), o uso do operador argumentativo (só) ${ }^{10}$ e o aumento no volume da voz (TRÊS DIAS), revelam sua intenção de intensificar a avaliação negativa e, assim, reforçar a identidade de profissionais dos reclamados como oportunistas e interesseiros. A questão de irem até seu local de trabalho para receberem é outro fator que também ganha relevo no piso conversacional de Sandra quando esta usa a expressão que indica recorrência (isso aconteceu duas vezes, linha 65). O comportamento dos reclamados descrito pela reclamante foge às normas sociais ou institucionais ${ }^{11}$ e projeta avaliações negativas sobre o outro. Essas avaliações não estão explícitas na narrativa, mas podem ser inferidas a partir dos fatos objetivos trazidos ao discurso para sustentar as opiniões. Nesse caso, as sustentações objetivas (eles trabalhavam TRÊS DIAS e só iam pra receber dinheiro) constituem a base de realidade para o julgamento moral de alguém sobre o outro. A realidade social trazida ao discurso projeta valores ideológicos da sociedade à qual os participantes pertencem (SHI-XU, 2000).

Mais adiante, Sandra faz referência ao contato de seu esposo com o vidraceiro (linhas 66 e 68) para desconstruir a realidade constituída por Pedro de que havia problemas no projeto e na casa que impediam a continuidade de seu serviço. Para dar mais credibilidade à sua fala, Sandra, por meio de discurso reportado, anima a voz de um expert sobre o assunto, colocando em dúvida a versão dos reclamados (linhas 69 a 71) (aí o cara do vidro falou olha, vocês mandam fazer o acabame:nto que tem que ser feito depois

${ }^{10}$ De acordo com Koch (2009), esse operador tem como função introduzir um pressuposto (no caso, de que os reclamados não trabalhavam) e se orienta para sua afirmação total (queriam receber sem ter trabalhado o suficiente para isso).

${ }^{11}$ Em algumas situações pode até incidir como crime de acordo com o Código de Defesa do Consumidor que no seu artigo 71 proíbe utilizar, na cobrança de dívidas, de ameaça, coação, constrangimento físico ou moral, afirmações falsas incorretas ou enganosas ou de qualquer outro procedimento que exponha o consumidor, injustificadamente, a ridículo ou interfira com seu trabalho, descanso ou lazer. 
a gen- quando você puder vocês encaixam o vidro). Aqui, há outro recurso argumentativo com carga ideológica marcante, pois socialmente quando se cita a fala de um especialista no assunto, o que a teoria da argumentação chama de argumento de autoridade $^{12}$, desloca-se do locutor a responsabilidade pelo que está sendo alegado, ao passo que agrega mais credibilidade à afirmação.

Na continuidade de seu relato, excerto (3), a reclamante segue a descrição dos problemas que ocorreram na casa, agora mostrando imagens do forro.

\section{Excerto 4: Olha pro cê vê}

\begin{tabular}{|c|c|c|}
\hline 3 & & $\begin{array}{l}\text { [olha o estado da minha sala!] isso aqui não- olha- o cara } \\
\text { do gesso, o outro, falou... gente- olha is-olha aqui-, tudo }\end{array}$ \\
\hline 0 & Pedro: & [essa sala eu falei que não] vai \\
\hline & & roveitar porque [ele interrompeu. não, não tem jeito. não \\
\hline 9 & Sandra: & [não tem jeito a cozinha, ] o forro qu \\
\hline & & le colocou (.) >eu preciso dar< [TRÊS mãos de massa: (.) pr \\
\hline & & tirar as imperfeições]= \\
\hline & edro & [nã - não (.) não \\
\hline 3 & $\mathrm{Fla}$ & ['aqui, seu Pedro, deixa ela falar $\left.{ }^{\circ}\right]$ \\
\hline 94 & ar & =três mãos de MASSA, (.) cê coloca o gesso já é um serviç \\
\hline 85 & & CARO, pra te-pra di- diminuir ${ }^{\circ}$ a despesa de massa ${ }^{\circ}$, todo \\
\hline 96 & & meu teto que ele colocou forro liso eu preciso de <três \\
\hline ค7 & & mãos de MASSA>. os três pintores que foram lá falaram nós \\
\hline 08 & & temos que dar três mãos de massa >pra tirar a imperfeição< \\
\hline 9 & & por que o tempo inteiro aqui >tudo trincado<. as placa \\
\hline 10 & & toda- você vê, o que eles já passaram lá olha >pro cê vê \\
\hline & & você vê as trincas as falhas, as faltas. é tudo um \\
\hline & & porqueira, uma porqueira .isso aqui é uma só. >só pro cê vê \\
\hline & & tudo quebrado (.) a \\
\hline & & tudo quebrado. a minha sala tá assim. isso aqu \\
\hline & & inha sala ó. \\
\hline
\end{tabular}

O excerto acima mostra a reclamante apresentando algumas fotos do trabalho dos reclamados em sua casa. Repetindo por quatro vezes o verbo (olha) e fazendo uso de dêiticos espaciais (isso, aqui), Sandra reafirma a má qualidade do serviço oferecido pelos reclamados (linhas 93 a 95). As fotos são apresentadas com valor de prova material, de evidência factual, funcionando como recurso para que sua fala não seja assumida apenas como uma opinião subjetiva, mas como um fato objetivo. Sobre isso, Shi-xu (2000) mostra que, quando fatos da realidade social são usados para sustentar opiniões, o caráter subjetivo e objetivo dos significados se tornam fundidos.

Na sequência, Pedro corrobora as sustentações de Sandra de que o gesso colocado na sala não poderá ser aproveitado, mas responsabiliza a interrupção feita pelo marido da reclamante como causa dos problemas (linhas 96 e 98 ).

Nas linhas 99 a 101, Sandra alega que será preciso dar três mãos de massa para tirar as imperfeições do forro da cozinha. A reclamante, utilizando mais uma vez da variação na tonicidade vocal em algumas palavras, avalia negativamente o trabalho dos reclamados como imperfeito (TRÊS mãos de [massa: (.) pra tirar as imperfeições). Pedro, na tentativa de se defender das acusações,

${ }^{12} \mathrm{O}$ argumento de autoridade consiste na utilização de "[...] atos ou juízos de uma pessoa ou de um grupo de pessoas como meio de prova a favor de uma tese [...]" (PERELMAN; TYTECA, 2005, p.348). 
tenta tomar o turno para si, sobrepondo sua voz à de Sandra (linha 102). Entretanto, é impedido por Flávia, que tem a responsabilidade de gerenciar a alocação dos pisos conversacionais, e garante que a reclamante prossiga (linha 103).

$\mathrm{Na}$ continuidade, a contratante acrescenta à sua narrativa a questão do gasto extra que terá devido à má qualidade do trabalho prestado (linhas 104 a 107). Para dar relevo à sua opinião, Sandra repete três vezes o fato de ter quer dar mãos de massa a mais para cobrir as imperfeições. Além das repetições, para ser mais enfática, em alguns pontos da fala há a elevação do tom de voz (linhas 104, $105,107)$. A fim de reforçar sua argumentação, a reclamante repete a mesma afirmação uma quarta vez, mas agora faz uso do discurso reportado ao animar a voz dos pintores que viram a obra (linhas 107 a 109).

Sandra segue mostrando fotos com as falhas deixados pelo prestador de serviço, e faz isso de forma muito contundente ao utilizar expressões que funcionam como dêiticos espaciais (você vê, olha pro cê vê, só pro cê vê, ó. isso aqui) e apontam os problemas na obra (linhas 110, 111, 112, 113). Além disso, avalia o serviço recebido como "imperfeito" e "porqueira" (linhas 108 a 112) reforçando, dessa forma, a identidade dos reclamados como maus profissionais.

Na continuação, Pedro tenta desconstruir a identidade negativa que a reclamante vem sustentando de seu trabalho.

\section{Excerto 5: $O$ barato sai caro}

$\begin{array}{lll}160 & \text { Pedro: } & \text { >a gente tem servi-<, a gente tem serviços bons e executados, } \\ & \text { tanto é que nós vivemos disso há dezesseis anos. como você } \\ 161 & \text { não entende, (.) eu não vou discutir [contigo] } \\ 162 & & \\ 163 & \text { Sandra: } & \text { [infeliz]mente infelizmente sabe. por causa de duzentos e } \\ 164 & \text { cinquenta reais, eu deixei de fechar com uma firma que é: : } \\ 165 & (.) \text { que tem credibilidade na cidade. infelizmente! >sabe } \\ 166 & \text { aquilo< o barato sai caro por causa de duzentos e cinquenta. } \\ 167 & \text { eu pondo tudo de melhor na minha casa, por causa de <duzentos } \\ 168 & \text { e cinquenta reais> (.) eu tô tendo essa <amolação>. é uma } \\ 169 & \text { coisa que já tinha que tá pronta. o (a menina que [(fez este } \\ 170 & \text { projeto disse que o projeto tinha que tá pronto há muito } \\ 171 & \text { tempo) }{ }^{\circ} \text { ] }\end{array}$

Pedro inicia a sequência de conflito (5), utilizando, uma vez mais, o elemento do senso comum com valor ideológico positivo, tempo de serviço, para construir uma imagem positiva de si e de seu trabalho, pois se acredita que quem possui muito tempo fazendo algo se torna experiente e, portanto, bom naquilo que faz. Na continuação, para deslegitimar e desacreditar as alegações da reclamante, Pedro ancora-se em uma convenção cultural, de que quem não entende de determinado assunto não pode fazer juízo de valor sobre ele. Assim, o reclamado avalia negativamente a competência de Sandra para fazer julgamentos de seu serviço (linhas 160 a 163 ). Sobre isso, Shi-xu (1992) sugere que as avaliações transmitem uma crença ideológica, por expressar uma moral partilhada ou aceitável, uma ação avaliativa pela qual algum valor ou norma sócio-cultural é adotado.

Sandra, sobrepondo sua voz, toma o turno, iniciando com o uso do item avaliativo "infelizmente" que, neste caso, especificamente, foi usado para acentuar o arrependimento de ter feito contrato com a empresa Super Gesso, que era a mais barata, e não outra com maior credibilidade (linhas 164 a 166). A reclamante também faz uso de um elemento do senso comum, o ditado popular "O barato sai caro" (linha 167), que tem um valor ideológico negativo, pois se subentende que o de menor valor é de pior qualidade. Com essa estratégia, Sandra insiste na construção da identidade daqueles que prestaram serviço em sua casa como sendo maus profissionais. Essa ideia é defendida também quando faz menção ao fato de que a obra já deveria estar terminada (linha 170).

Por fim, faz uso novamente do discurso reportado (linhas 171 e 172), animando a voz da projetista da obra. Aqui, o termo "menina" não tem a mesma conotação quando usado no exceto 2 , linha 41 , mas marca a autoria do projeto sendo de uma mulher, especialista na questão, que avalia negativamente a obra realizada pelos reclamados. Isso ratifica a afirmação de Thompson (2011) de que se 
pode interpretar uma forma simbólica como sendo ideológica em um determinado contexto e como não sendo em outro. Ou mais ainda, que o valor ideológico de uma forma simbólica pode variar de acordo com o contexto de uso e a meta interacional.

\section{CONSIDERAÇÕES FINAIS}

A análise dos dados mostrou sequências de conflito geradas a partir da divergência entre as versões dos fatos apresentadas por reclamante e reclamado. Durante a audiência, os participantes não se detiveram à descrição objetiva dos acontecimentos, mas, a partir de um jogo de atribuições de responsabilidades, buscaram desqualificar o outro, por meio não só de narrativas factuais, como também fazendo uso de formas discursivo-culturais que veiculam valores ideológicos específicos.

Observou-se que, durante a construção e sustentação do objeto da reclamação, os participantes utilizaram, como uma das estratégias para conseguir êxito no conflito, a projeção de identidades com o intuito de manter uma imagem positiva de si, enquanto atribuíam ao seu opositor um status negativo.

A reclamante, por exemplo, dispensou grande parte de sua narrativa para projetar aos reclamados a identidade de maus profissionais. Nesse sentido, recorreu a recursos paralinguísticos, como variações prosódicas, e a estratégias linguístico-discursivas, como o uso de repetições, operadores argumentativos, discursos reportados e narrativas factuais. Também mostrou evidências materiais, como fotos, para confirmar sua avaliação negativa do trabalho realizado pelos reclamados. Fez uso ainda de elementos baseados no senso comum, como no caso de ditados populares, que possuem um valor ideológico culturalmente aceito e partilhado. Por fim, como postula Shi-xu (2000), os fatos objetivos narrados pela reclamante, especialmente no excerto (3), serviram para fornecer status de factualidade à opinião subjetiva de que os reclamados eram maus profissionais.

No caso dos reclamados, representados nos excertos por Pedro, a fala focou prioritariamente na tentativa de desconstruir a imagem negativa imputada pela reclamante ao seu trabalho, ao mesmo tempo em que atribuía a si a identidade de bons profissionais. Para isso, o reclamado usou elementos da coletividade cultural, como, por exemplo, a questão de terem sido indicados para o trabalho, $\mathrm{o}$ que demonstra reconhecimento profissional; o tempo de serviço como indicador de experiência na área, o que os caracteriza como pessoas qualificadas; discursos reportados para agregar valor à sua argumentação e determinadas escolhas lexicais. Todos esses elementos expressam valores ideológicos evidenciados e determinados na prática interacional (BILLIG, 1991; THOMPSON, 2011) que orientam a significação de sentidos para alcançar metas específicas.

A análise realizada mostrou que a dimensão ideológica, na audiência investigada, teve como função, na construção de identidades, orientar a significação do sentido para uma estrutura reconhecida e partilhada socialmente. Já as identidades construídas serviram como recurso argumentativo direcionado a propósitos interacionais específicos: ora para validar a afirmação da reclamante de que os reclamados eram maus profissionais e, por isso, o serviço recebido era de má qualidade, o que levou à paralisação da obra; ora para deslegitimar as acusações da reclamada e sustentar a identidade de bons profissionais, o que não justificava a paralisação da obra por parte dos contratantes.

Este trabalho confirma a proposta de Billig (1991) de que o sujeito social não é um ser ingênuo e passivo diante da ideologia, mas consegue valer-se dela em suas práticas sociais. E, também, que é na interação que os significados ideológicos das formas discursivas são negociados e definidos (THOMPSON, 2011). A análise mostrou que as identidades foram coconstruídas e negociadas durante a interação (BUCHOLTZ; HALL, 2004; OCHS, 1993; MOITA LOPES, 2001), não se tratando, portanto, de um fenômeno fixo e rígido, mas de um construto sociointeracional.

Por fim, queremos registrar que, embora a situação de interação analisada neste estudo seja singular, há traços convencionais cuja repetição é provável em outras interações do tipo, como, por exemplo, o conflito de posições e a invocação de autoridade. Entretanto, ressaltamos que o uso da dimensão ideológica como base de realidade para fornecer status de factualidade a opiniões subjetivas (SHI-XU, 2000) - a construção ideológica dos "fatos" - é um resultado válido tão e somente para este contexto específico, necessitando ser confirmado em outras audiências do gênero. 


\section{REFERÊNCIAS}

BILLIG, M. Ideology and opinions: studies in rethorical psychology. London: Sage, 1991.

BRASIL. Lei nº 8.078, de 11 de setembro de 1990. Código de Defesa do Consumidor. Diário Oficial da União, Brasília, DF, 12 de set. 1990. Disponível em: http://www.planalto.gov.br/ccivil 03/Leis/L8078.htm. Acesso em: 21 jul. 2017.

BRENNEIS, D. Language and disputing. Annual Review of Anthropology, Los Angeles, California, v. 17, p. 221-237, 1988.

BUCHOLTZ, M.; HALL, K. Language and identily. In: DURANTI, A. A Companion to Linguistic Anthropology. Oxford: Blackwell Publishing, 2004. p. 369-394.

CORONA, M. D. Fala-em-interação cotidiana e fala-em-interação institucional: uma análise de audiências criminais. In: LODER, L. L.; JUNG, N. M. Análises de fala-em-interação institucional: a perspectiva da Análise da Conversa Etnometodológica. CampinasSP: Mercado das Letras, 2009. p. 13-44.

DENZIN, N. K.; LINCOLN, Y. S. A disciplina e a prática da pesquisa qualitativa. In: (org.) O planejamento da pesquisa qualitativa: teorias e abordagens. Porto Alegre: Artmed, 2006. p. 15-42.

DREW, P.; HERITAGE, J. Analyzing talk at work: an introduction. In: Talk at work: interaction in institutional settings.

Cambridge: Cambridge University Press, 1992. p. 3-65.

GOFFMAN, E. Frame analysis. New York: Harper \& Row, 1974.

GOFFMAN, E. A situação negligenciada. In: RIBEIRO, B. T.; GARCEZ, P. M. (org.) Sociolingüística interacional. São Paulo: Loyola, $2002[1964]$.

GOFFMAN, E. Footing. In: RIBEIRO, B. T.; GARCEZ, P. M. (org.). Sociolingüística interacional. São Paulo: Loyola, 2002 [1979]. p. 107-148.

GRIMSHAW, A. D. Conflict talk. Cambridge: Cambridge University Press, 1990.

GUMPERZ, J. J. On interactional sociolinguistic method. In: SARANGI, S.; ROBERTS, C. (org.)/. Talk, work and institutional order: discourse in medical, mediation and management settings. New York: Mouton de Gruyter, 1999. p. 453-471.

GUMPERZ, J. J. Convenções de contextualização. In: RIBEIRO, B. T.; GARCEZ, P. M. (org.). Sociolinguística Interacional. São Paulo: Edições Loyola, 2002 [1982].p. 149-182. 
HALL, S. Quem precisa da identidade? Tradução de Tomaz Tadeu da Silva. In: SILVA, T. T. (org.). Identidade e diferença: a perspectiva dos estudos culturais. Petrópolis: Vozes, 2000 [1996]. p. 103-133.

KOCH, I. G. V. A inter-ação pela linguagem. São Paulo: Contexto, 2009.

MARX, K.; ENGELS, F. A ideologia alemã. Tradução de Álvaro Pina. São Paulo: Expressão Popular, 2009.

MAYNARD, D. W. Inside plea bargaining: the language of negociation. New York: Plenum, 1984.

MOITA LOPES, L. P. Práticas narrativas como espaço de construção das identidades sociais: uma abordagem socioconstrucionista. In: RIBEIRO, B. T.; COSTA LIMA, C.; LOPES DANTAS, M. T. (org.). Narrativas, Identidades e Clínica. Rio de Janeiro: Edições IPUB/CUCA, 2001, p. 55-71.

OCHS, E. Constructing social identity: a language socialization perspective. Researchon Language and Social Interaction, v. 26, n. 3 , p. 287-306, 1993.

OLIVEIRA, A. E. A prática discursiva de perguntar em situações de conflito: uma abordagem interacional. 2010. 154f. Dissertação (Mestrado em Linguística). Departamento de letras, Universidade Federal de Juiz de Fora, Juiz de Fora, 2010.

PERELMAN, C.; OLBRECHTS-TYTECA, L. Tratado da argumentação: a nova retórica. 2. ed. Tradução de Maria Ermantina G. G. Pereira. São Paulo: Martins Fontes, 2005.

SACKS, H.; SCHEGLOFF, E. A.; JEFFERSON, G. Sistemática elementar para a organização da tomada de turnos para a conversa. Tradução de Maria Clara Castellões de Oliveira et. al. Veredas, Juiz de Fora, MG, v. 7, n. 1-2, p. 11-73, 2003 [1974].

SCHIFFRIN, D. Interactional sociolinguistics. In: SCHIFFRIN, D. Approaches to discourse. Massachussettts/Oxford: Blackwell Publischers, 1994. p. 97-136.

SHI-XU. Argumentation, explanation, and social cognition. Text: an interdisciplinary journal for the study of discourse, New York, v. 12, n. 2, p. 263-291, 1992.

SHI-XU. Opinion discourse: Investigating the paradoxical nature of the text and talk of opinions. Research on Language and Social Interaction, v. 33, n. 3. p. 263-289, 2000.

THOMPSON, J. B. Ideologia e cultura moderna: teoria crítica na era dos meios de comunicação de massa. 9. ed. Petrópolis: Vozes, 2011.

VUCHINICH, S. The sequential organization of closing in verbal family conflict. In: GRIMSHAW, A. Conflict talk: sociolinguistics investigation of arguments in conversation. Cambridge: Cambridge University Press, 1990.

YIN, Roberto K. Estudo de caso: planejamento e métodos. 2. ed. Porto Alegre: Bookmam, 2001.

\section{(1) $\circledast \circledast$}




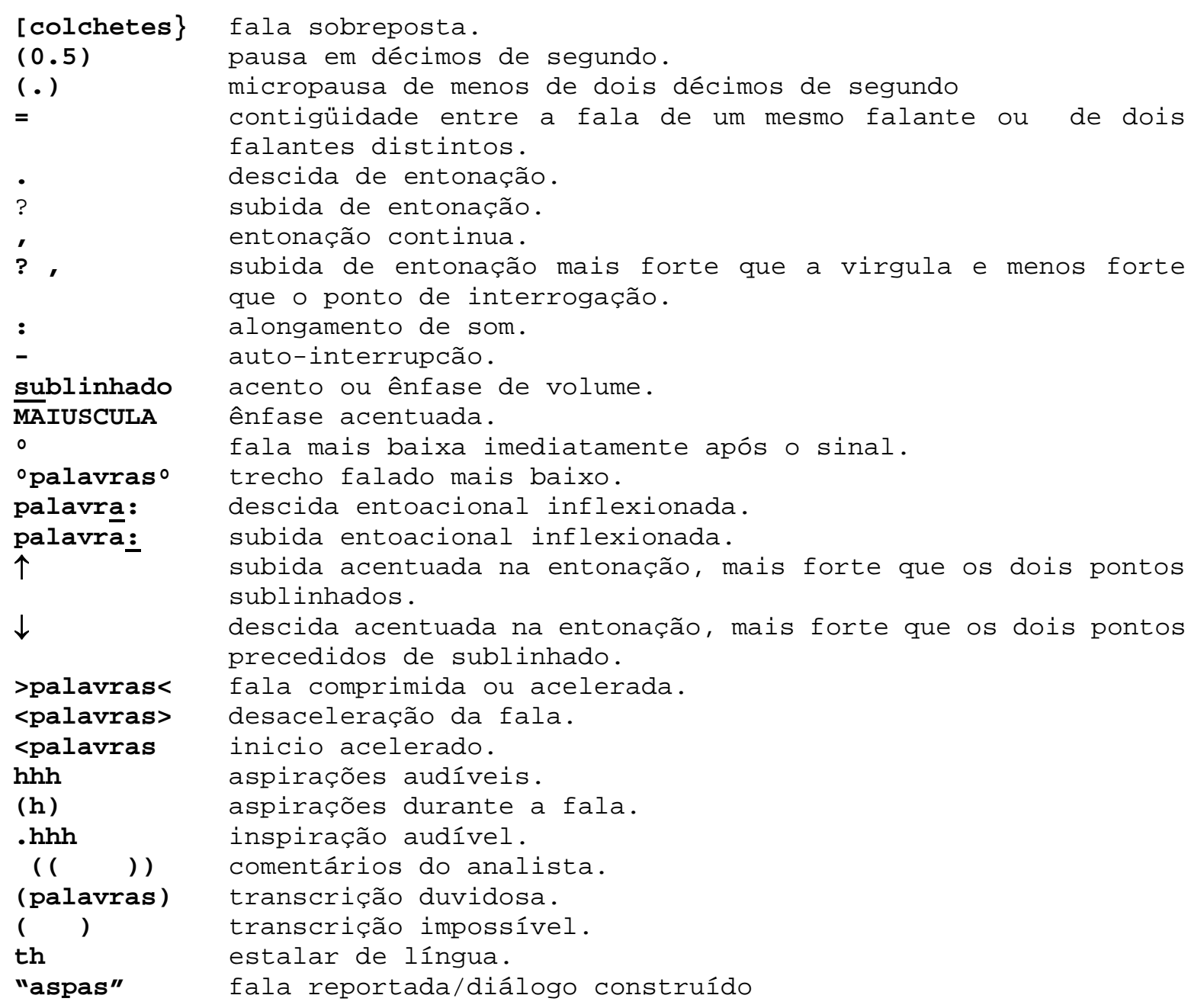

